\title{
An Unusual Accidental Kerosene Poisoning. Case Report
}

\author{
*Baba Usman Ahmadu (MBBS, MHPM, FMCPaed), \\ Apollos Nachanuya Chafi (MBBS), Harry ClaphtonDifirwiti (MBBS), \\ Adzu Yusuf (MBBS), ${ }^{1}$ Ambe Jose Pwavimbo (MBBS,FMCPaed)
}

\author{
Department of Paediatrics, Federal Medical Centre, Yola, Adamawa state, Nigeria. \\ ${ }^{1}$ Department of Paediatrics, University of Maiduguri Teaching Hospital, Borno state, Nigeria \\ *ahmadu4u2003@yahoo.com
}

\begin{abstract}
Kerosene aspiration is toxic and harmful to children. Cases of chemical pneumonitis from kerosene poisoning had been reported in older children. It is however more worrisome to see such cases in infants. Here is a case study of a two month old infantwho was accidentally given kerosene in place of water. The child was diagnosed of chemical pneumonitis from kerosene ingestion and aspiration. The patient responded well to medication, recovered fully and discharged home after her care-giver was counselled on kerosene (poison) and drug prevention. We advised that hospital efforts should further be complimented by strengthening and supporting institutions saddled withdrug, food and poison control prevention like National Agency for Food, Drug Administration and Control (NAFDAC) in Nigeria.
\end{abstract}

Keywords: Kerosene chemical pneumonitis, Kerosene poisoning, infant, Accidentprevention and control, FMC-Yola, Nigeria.

\section{INTRODUCTION}

Kerosene is a hydrocarbonmixture of paraffin and naphthalene, which is widely used for cooking meals, heating andlightning of home in developing countries like Nigeria (1-3).Gas, electricity and other forms of energy are used for similar purposes in developed countries abroad. Developing countries are backwards in terms of alternative source of energy,as such people from those regions of the world mostly rely on kerosene, which is more accessible (3). Generally, five percent of childhood poisoning and a quarter of under-fivedeathare from accidental hydrocarbon ingestion, kerosene being foremost (2). Kerosene poisoning mostly affectrespiratory, centralnervous and gastro-intestinal systems, rarely are other organs involved(1).Chemical pneumonitis and bronchitis are the most common features of kerosene poisoning (1-3).

Kerosene isusually kept in water containers or in polythene bagsparticularly in our communities; this has ledto its accidental ingestionby children who often thought is water. Rarely is kerosene poisoning heard off in infants below three months of age and vast literature search on this issue showed dearth of information (1-5). Reason could be due to non-attainment of relevant motor milestones required by subjects to explore their surroundings. Herein, we report a case of aspiration pneumonitis secondary to kerosene ingestion in a two month old infantwho has been on predominant breastfeeding and cared for by both parents and maternal grandmother. The aims of thecase study were to describe the clinicalpresentationand optimal management of kerosene poisoning. To enlightened care-givers on kerosene (poison) and drug control preventive measures both at the hospital and at agency level like NAFDAC.

\section{CASE Summary}

MIB, a two months old infant was admitted into Federal Medical Centre (FMC), Yola on account of accidental kerosene ingestion. Child was doing well until when grandmother inadvertently took kerosene which was in a water container and poured it into the feeding bottle and gave the child. Child started having cough and vomiting after ingesting the product. She later developed difficulty in breathing, examination revealed a well fed childweighing $4.9 \mathrm{~kg}$ with a temperature of $38 .{ }^{\circ} \mathrm{C}$. she was in respiratory distress, respiratory rate of 80 breaths per minute not cyanosed, flaring of alai nasai with bilateral fine crepitation. The heart rate was 130 beats per minute, heart sounds were $S_{1}$ and $S_{2}$, no murmurs. Abdominal and central nervous systems were essentially normal. Diagnosis of aspiration pneumonitis was made clinically and patient was placed on intranasal oxygenand intravenous fluids. 
She had parental antibiotic and was on nil per oral. There was improvement after 48 hours; temperature came down to $37.3^{0} \mathrm{C}$,respiratory distress subsided, chestbecame clear clinically. Intravenous fluid was discontinued and patient commenced on oral feeding. Intravenouscefuroxime was then changed to the oral form. She was discharged on the $5^{\text {th }}$ day of admission after care giver was counselled on preventive measures that included exclusive breastfeeding and safe storage of kerosene. Chest radiograph and Electrocardiograph were notobtained due to financial constrain. Her packed cell volume was $36 \%$, White Blood Cell Count was $6.1 \times 10^{9}$, neutrophil was $66 \%$, eosinophil was $4 \%$ and lymphocyte was $30 \%$.The blood picture showed reversal of neutrophil- lymphocyte ratio suggestive of bacterial infection for her age bracket. However, blood culture was negative. Follow-up a week after discharge revealed a stable child.

\section{DISCUSSIONS}

In developed states, the use of alternative source of energy in homes had substantially replaced kerosene. This is not so in developing countries where kerosene is still extensively used. Therefore, cases of accidental kerosene poisoning in children could be found much more in developing than in advanced societies (1-5).Kerosene is a liquid mixture of chemicals produced from distillation of crude oil, if a child accidentally aspirates it, that child stand the risk of having chemicalpneumonia as was the case here.Like most chemicals, the amount of kerosene associated with adverse health effects must be above a certainlevel. Unfortunately, threshold toxicity value for kerosene is still not very clear partly because only small quantity less than $30 \mathrm{mls}$ areingested at any given time $(2,3)$. On the contrary,some investigators had published children who survived ingestion of up to $1.7 \mathrm{~g} \mathrm{~kg}^{-1}$ of kerosene. They further stated that doses ranging from approximately 2 to $17 \mathrm{~g} \mathrm{~kg}^{-1}$ are associated with about 30\% fatality (4-7).Lung exposure tokerosene vapor may cause non-specific signs such as cough, vomiting, difficulty in breathing, fever, dizziness, headache etc.

Cough, vomiting, difficulty in breathing and fever were found on the index case at presentation. The observation corroborated that of Ashir et al (1) in Maiduguri, Nagi and Abduallah (2) in Iraq. The respiratory symptoms and signs produced by aspiration pneumonia could be attributed to some properties of kerosene being its volatility, vapor pressure and surface tension $(2,3)$. That is why it is pertinent not to induce vomiting in a child who had ingested kerosene. Vomiting after kerosene ingestion increases a child's vulnerability to aspiration which in turn leads to chemical pneumonia.Several researchers had reported poor systemic absorption of kerosene from the gastrointestinal tract, therefore, respiratory or even nervous systems manifestations are due to hypoxia and acidosis from injured lungs and not due to systemic absorption (1-6). Risherand Rhodes (4) in their study of toxicological profiles for fuel oils in the United States experienced more than half of children presenting with kerosene ingestion are asymptomatic. Moreover, those with chemical pneumonitis will in most cases respond to treatment like the present case. Mortality is low because kerosene has low volatility which allows air concentrations at approximately $100 \mathrm{mg} / \mathrm{m}^{3} \mathrm{known}$ as NOAEL (no observable adverse effect level) (2-4, 7). Nonetheless, however, high grade fevercan heighten kerosene toxicity by inducing narcotic effects like narcolepsy, cataplexyand death $(8,9)$.Other symptoms like dizziness and headache could not be picked in our patient due to her very young age.

Care givers of current case could not complete the child's investigation. Chest radiograph and electrocardiograph could not be obtained because of lean financial resource on the path of the care givers.Similar finding was made by Authors from Al-Khansa Children's Hospital in the city of Mosul (2). Majority of patients diagnosed of kerosene poisoning are from poorfamilies, living in crowded conditions wherekerosene use is extensive coupled withsuboptimal care andsupervision of children (2, $3)$.

Standard best practice entails removalof patient from site of kerosene exposure, oxygen delivery, maintaining a clear airway withadequate ventilation and applying other measures as indicated by the patient's clinical condition (1-3).This platform was followed in the course of managing our patient. Worthy of note is that gastric lavage or inducedvomiting should be avoided. Consider gastric aspiration within one hour of kerosene ingestion or if very large amounts was taken or there is concern about another toxin, provided the airway can be protected (1-3).Patients who ingested little quantity of kerosene and are not showing symptoms of aspiration pneumonia,such patients can be observed at home under supervision for about six hours, with an advice to go to hospital immediately if features emerge (3). 
The toxic and harmful effects of kerosene entails thatcare must go beyond secondary prevention by educating care-givers on proper kerosene storageusing locked containers,kept in a safe place. Induced vomiting or gastric emptying and the use of feeding bottle at home should be discouraged while promoting exclusive breastfeeding, good hygiene and sanitation and immunization. These primary preventive measures were discussed with the child's care-givers in the form of counselling and education at the hospital. Other relevant body like NAFDAC must carry the preventive crusade in-line with Drug, Food and Poison control policy to care-givers at home, wards or communities directly or by using media outfits etc. Very rarely does a case of kerosene poisoning require tertiary or quartnary prevention.

\section{Conclusions}

Kerosene poisoning is associated with majority of childhood chemical pneumonia. Primary preventive measures that need to be considered to avoid accidental exposure of aninfant to it are first, storing kerosene in locked containers placed in a safe environment. Secondly,the practice and promotion of exclusive breastfeeding in children from birth up to six months be encouraged, thereafter, complimentary feeds be gradually instituted. Thirdly, immunization, proper hygiene, environmental sanitation and avoidance of bottle feeding must be practiced. Where the accident had occurred, patient should be taken to the hospital for quality care by way of secondary prevention. In some remote cases the continuum of care could involve tertiary and or quaternary preventions. Induced vomiting at home should be avoided.

\section{ACKNOWLEDGEMENT}

We thank Ja'afaru UN and Adamu $\mathrm{H}$ for their technical assistance.

\section{REFERENCES}

[1] G.M Ashir, A.I Rabasa, M.M Gofama, S.M Yahaya. Tension Pneumothorax following an Accidental Kerosene Poisoning: A Case Report. Niger Med J2009; 50(4):95-6.

[2] NA Nagi, ZA Abdulallah. Kerosene poisoning in children in Iraq. Postgrad Med J 1995; 71: 419 22.

[3] RP Chilcott. Kerosene (Fuel Oil).Health Protection Agency Compendium of Chemical Hazards. 2006, Version 1. www.hpa.org.uk.

[4] Risher J. F, Rhodes S. W. Toxicological profiles for fuel oils. USDepartment of Health and Human Services 1995.

[5] Dudin A.A, Rambaud-CoussonA, Thalji A, Jubeh II, Ahmad H.M, Libdeh B.A. Accidental kerosene ingestion: a 3-year prospective study. Ann Trop Paediatr 1991; 11: 155-61.

[6] Mann MD, Pirie DJ, Wolfsdorf J. Kerosene absorption in primates. J Pediatr 1977; 91: 495.

[7] Ritchie G.D, Still K.R., Alexander W.K, Nordholm A.F, Wilson C.L, Rossi J.3 ${ }^{\text {rd }}$, Mattie D.R. A review of the neurotoxicity risk of selected hydrocarbon fuels. J Toxicol Environ Health B Crit Rev 2001; 4:223-312.

[8] Bebarta V, DeWitt C. Miscellaneous hydrocarbon solvents. ClinOccup Environ Med 2004; 4:45579.

[9] Moller J.C, Vardag A.M, Jonas S, Tegtmeyer F.K. Poisoning with volatile hydrocarbons. 3 cases and a review. MonatsschrKinderheilkd 1992;140:113-6. 